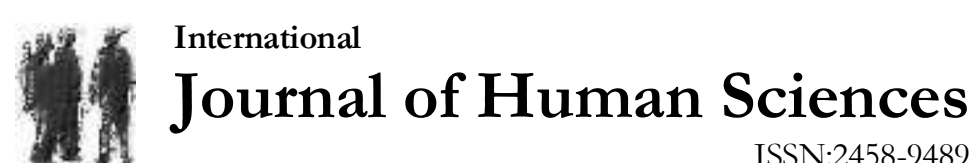

Volume 17 Issue 2 Year: 2020

\section{Testing the effectiveness of a gym orientation program}

\author{
Dimitri Koutsoubakis ${ }^{1}$
}

\begin{abstract}
The study was set at a commercial Fitness Center facility based in Dubai, UAE, and aimed to test the effectiveness of a Gym Orientation Program designed to help new members with little-to-no training experience acclimatize to the facility and to fitness training.

The practical end of all orientation programs is to ameliorate Member Retention; the purpose of the present study was to investigate whether the Gym Orientation Program supported member retention via its impact on intermediary perceptual constructs.

A longitudinal design was used to collect data at three distinct points in the customer journey, onboarding, completion of the Gym Orientation Program, and at Membership Renewal, one year after joining. Questionnaire instruments were adapted from studies on Student Retention in Higher Education.

Multivariate analysis of covariance and multiple regression were used to determine whether Gym Members who participated in the Gym Orientation Program differed significantly from those who did not on the basis of institutional and social integration constructs. Multiple Regression was used to assess the impact of the integration metrics on self-reported intent to persist.

Results suggest that the Gym Orientation Program promoted significantly increased levels of integration and intent to persist, ultimately leading to increased Member Retention. In terms of practical implications, the findings support the conclusion that it is possible to design and implement effective interventions that explicitly aim to increase the sense of institutional and social belonging in order to increase Member Retention.

The study adopts an original, interdisciplinary approach by deploying the methodological paradigm deployed and refined over five decades in the field of student retention scholarship within Higher Education, underlining the conviction that there is much to be gained by adopting an interdisciplinary perspective.
\end{abstract}

Keywords: Retention; orientation; integration; persistence.

\section{Introduction}

The subject matter of the present paper is the phenomenon of Member drop-out from private, commercial fitness organizations; for the sake of simplicity and clarity we will refer to such organizations as "Gyms" herein, even though there exist various alternative commercial designations, e.g., "Fitness Center," "Fitness Club," etc.

\footnotetext{
${ }^{1}$ Ph.D., dkoutsoubakis@hotmail.com
} 
Member Attrition - the drop-out and commercial loss of Gym Members from their chosen Gym - is a well-studied topic, as is the positive corollary, Retention, defined as the array of strategies and tactics deployed to encourage Gym Members to persist and stay loyal to their chosen Gym (Macintosh \& Doherty, 2007; Gonçalves \& Diniz, 2015).

Obviously, Member Attrition is problematic to commercial Gyms in a direct economic sense, due to the direct and immediate erosion of vital membership revenues, but also strategically (in terms of brand value), and even ethically, in terms of associated effects on human potential, health, well-being, etc.

Data compiled by IHRSA (https://www.ihrsa.org/improve-your-club/a-simple-solutionfor-health-club-attrition) indicate that for every gym member who fails to renew a membership, the average cost in the U.S. can run to $\$ 674$ in annual revenue, over and above an additional average out-of-pocket of approx. \$119 in marketing and sales costs per "replacement" member. But this simplistic bottom-line approach misses the real mark - because member retention is about maximizing the lifetime revenue of each member. According to the IHRSA, increasing customer retention by $5 \%$ leads to a profit increase of between $25 \%-95 \%$ percent, over a five-fold "multiplier effect." Over and above, the success rate of renewing an existing membership is between $60 \%$ $70 \%$, compared against the success rate of new, acquisition membership sales, running at $5 \%-20 \%$.

The logic behind strategic retention planning is therefore straightforward: In order to safeguard both revenues (a direct problem) and other indirect threats, proactively minded Gym Management teams aim to increase member retention rates by developing and implementing suitable policies and programs, yet there is no published research on specific gym orientation programs (Lynch et. al.,2003; Mavropoulou et al., 2013).

In other domains where the issue of retention is front-and-center, such as Higher Education, the process of retention-program development based on theoretical models of the attrition process has been underway for close to five decades (Bean, 1980; Milem \& Berger, 1997; Tinto, 1975, Yucel-Aybat et.al., 2018), and has resulted in a variety of programmatic interventions aimed at enhancing the degree and quality of student-institution integration, ultimately impacting student retention. This emphasis and rigor in terms of conceptualizing attrition/retention theoretically in order to lead to empirically testable proposals for effective deployment of realworld interventions have not been matched in the Fitness Industry.

There is arguably much to learn by looking at the domain of Student Attrition in Higher Education; here, theoretical models of the attrition phenomenon generally stress the importance of academic and social involvement and integration (Astin, 1984, 1993; Bean, 1983; Pascarella, 1980). These theoretical models ultimately derive from much earlier work on suicide, perhaps the ultimate definition of attrition (Tinto, 1975), wherein conceptual latent constructs such as Social Integration and a sense of belonging are cast in the role of the prime explanatory variables.

Perhaps the most widely tested and empirically validated of these models, Tinto's Student Integration Model (Tinto, 1975, Kirby, 2015), conceptualizes attrition as a longitudinal process whereby initial levels of student commitments and goals are continually modified by the degree and quality of student interactions within the academic and social systems that comprise the institutional environment. These interactions determine subsequent goals and commitments and in turn effect persistence/withdrawal decisions.

\section{Purpose}

While the scope of the present paper does not extend to proposing and testing a theoretical model of Member Attrition for commercial Gyms, we nevertheless propose herein a conceptualization of Member Attrition based on the well-researched models used within Higher Education scholarship.

In Higher Education research, the evolution of the range of available retention interventions, programs, and policies has generally been guided by theoretical frameworks, but 
these have not drawn on any particular model, focusing instead on the broad conceptual consistencies of various approaches in order to propose effective real-world actions (Pascarella \& Terenzini, 1980, Williams et. al. 2018).

With this in mind, we adopt herein an approach based on a conceptual mapping of related constructs - whereas in Higher Education research the key latent variable constructs are Social and Academic Integration, in the context of studying Gym Member Attrition, we propose that the conceptually "mapped" concepts are Social and Institutional Integration respectively.

Given that in Higher Education the theoretical framework emphasizes the role of Social and Academic Integration, the various remediation / intervention programs that have evolved over the past five decades focus on trying to increase levels of student perceptions of Academic \& Social Integration, in order to subsequently increase Retention. A widely used practical example is the incorporation within a broad range of undergraduate programs of some form of on-boarding Orientation Program (Strumpf \& Hunt, 1993, Williams et. al. 2018).

Inspired by the deep body of related scholarship in Higher Education, the present paper examines the effect of a similar Orientation Program, this time designed for use at a commercial Gym, and focusing on reinforcing two key proposed determinants of Attrition/Retention: Institutional and Social Integration. The primary purpose of the present study is to determine whether an Orientation program adapted from scholarly work in the domain of Higher Education could be implemented in a commercial Gym context effectively, with a demonstrable positive impact on Member Retention. The rationale is simple yet compelling: confused, intimidated Members are unlikely to "bond" with the gym, by definition; they are unlikely to train frequently and consistently, and therefore unlikely to make self-perceived gains, unlikely to make friends, and ultimately unlikely to renew their Membership once it expires.

\section{Method}

\subsection{Place and Time of Study}

The study took place at a large commercial fitness center based in Dubai, UAE, between January 2019 and January 2020. The facility in question is referred to herein as "Gym X."

Gym X management includes member-retention research as part of its ongoing research activities in order to better understand the mechanisms of Member Attrition and thereby devise effective countermeasures. This is understood as a fundamental strategy aiming at creating and maintaining sustainable competitive advantage.

The Gym Orientation program was conceived of as a potential intervention to a recurring and troubling internal-research observation - in Customer Satisfaction surveys regularly deployed by management (bi-annually), a sizeable proportion of new Members reported feeling disoriented, confused, and "lost" within the large gym space - which, although consistently reported as being well-appointed, staffed, and equipped, was simultaneously reported as being intimidating.

\subsection{Population and Sample Selection}

The Gym Orientation program was designed to directly counteract persistent observed Member perception of a confusing, intimidating environment, in order to identify a means of intervention and correction. The population of the study, therefore, includes the open-ended total of all future Member Acquisitions.

As regards the sample: In January 2019 the entire entering "cohort" of new Members was asked to complete a simple on-boarding questionnaire immediately after purchasing their Membership plan. January is a seasonally a strong month for Acquisition sales, and January 2019 delivered 456 New Members, all of whom submitted complete, usable questionnaires.

The survey questionnaire was designed to measure prior expectations of the Gym experience and to operationalize key background variables for statistical control. 
Given that the Gym Orientation Program was designed specifically for those with little-tono gym experience, Members with extensive training experience were excluded from the sample pool, to be used as a control sample at the end of the 12-month longitudinal design period. This left 175 usable "Gym Novice" responses, and a remainder of 281 "Experienced User" responses.

Between January and April 2019, these 175 "Gym Novices" were offered the opportunity to participate in the 4-week Gym Orientation program voluntarily In April 2019, following completion of the Gym Orientation program, a second questionnaire was sent to the $N=175$ respondents.

The follow-up instrument was designed to measure Member perceptions of the initial 3Month Gym Experience. Members of the target N=175 Member cohort were repeatedly reminded via email and WhatsApp, and were accosted directly in the Gym by Coaches, Personal Trainers, and Reception staff to maximize the response rate.

Usable responses were ultimately received after a 1-month collection effort from 128 Members (73\% response). The pre-and-post data sets (1st from January 2019, 2nd from April 2019) were merged into a single longitudinal data set of $\mathbf{N}=\mathbf{1 2 8}$ respondents.

Of the 128 "Gym Novice" Members who completed both questionnaires, $\mathbf{7 0}$ participated in the Gym Orientation Program, while 58 did not.

\subsection{Type of Study}

The study was longitudinal in design, with an initial measurement followed by an intervention (the Gym Orientation program), followed by subsequent, post-intervention measurement. Given the commercial context, an experimental design was not possible, and this is an acknowledged limitation - Gym Members self-selected participation in the program, rather than being assigned randomly.

\subsection{Research Question}

The desired outcome of the Gym Orientation program was to promote greater levels of Member Retention by helping newly on-boarded Members understand and acclimatize to an otherwise intimidating environment. In terms of the informal theoretical model proposed herein, the object was to increase levels of perceived Institutional and Social Integration in order to foster the feeling of "belonging." In terms of implementation, given the commercial context, the Gym Orientation program was designed and marketed as a voluntary choice open to new on joining the Gym. The only enrollment criterion was that participating Members were self-reported Novices willing to participate in a 4-week program designed to help on-board people new to the Fitness / Gym environment.

The research question involves examining the internal validity of the proposed intervention - the Gym Orientation Program.

If the Gym Orientation program is indeed effective, then we should be able to demonstrate that new Members who participate in the Program exhibit significantly higher levels of Institutional and Social integration compared against peers who do not participate, controlling for background characteristics and other covariates.

Finally, these higher levels of Institutional and Social integration are posited to lead to higher levels of commitment and perseverance (as measured by the variable Persist), and ultimately to higher levels of actual, observed Member Retention.

\subsection{Hypothesis}

We base our conceptual framework herein on Tinto's model of Student Attrition (Tinto, 1975), which conceives of student attrition as a longitudinal, interactive process in which a number of direct perceptual antecedents of eventual persistence decisions are continually modified via a process of ongoing student interaction with the academic and social communities that comprise the educational institution. 
The interactions of students within these academic and social communities result in the development and evolution of perceptions of academic and social integration. These growing perceptions depend in turn on initial, background levels of goal commitment and a host of background characteristics that differentially predispose students to the attainment of goals in general.

Turning now to the context of Gym Member attrition in the fitness industry, the causal cascade is conceived as follows:

Member background characteristics and initial levels of motivation \& goal commitment differentially determine the extent and quality of institutional/social interactions in the Gym context, leading to the formation of Member perceptions of institutional/social integration and an ultimate sense of "belonging." It is these perceptions of institutional/social integration that ultimately lead to a decision to persist and persevere, or to drop out.

The hypothesis posed herein posits that new Gym Members who complete the Gym Orientation Program will exhibit significantly higher scores of institutional/social integration once background variables are statistically controlled. In the longer term (allowing for 12-month Membership cycles at Gym X), it was posited that those Members who participated in the Gym Orientation Program will exhibit significantly higher intention to Persist, and actual Retention, compared with those who did not.

\subsection{Data Collection}

Data collection spanned an entire year, commencing in January 2019 and ending in January 2020, in order to allow observation of actual Member attrition / retention over the lifecycle of a Gym X 12-month Membership plan. The sections below discuss the data collection methodology in detail.

\subsubsection{Data Collection Tools - the Instruments}

Data collection for the present study used 2 Questionnaire Instruments constructed by adapting selected source scales and items from the field of student retention research in Higher Education (Koutsoubakis, 1999):

(1) Pre: Entering Member Questionnaire (EMQ): January 2019

\section{Constructs measured:}

- Background characteristics - 2 items

- Initial Goal Commitment - 3 items

- Initial Institutional Commitment - 3 items

(2) Post: Continuing Member Questionnaire (CMQ): April 2019

\section{Constructs measured:}

- Secondary Goal Commitment - 2 items

- Secondary Institutional Commitment - 2 items

- Institutional Integration - 3 items

- Social Integration (SI) - 3 items

- Intent-to-Persist (Pers) - 1 item

(Please see Table 2 below for details)

Each item was measured via a standard 5-point Likert scale, ranging from $\{1=$ Strongly Disagree; to $5=$ Strongly Agree $\}$.

The final observation, in January 2020, was actual Retention among the $N=128$ participating Members; this was defined simply as Retention $=1$ for those Members who renewed their Memberships, versus Retention $=0$ for those who did not. 
Koutsoubakis, D. (2020). Testing the effectiveness of a gym orientation program. Journal of Human Sciences, 17(2), $469-484$. doi:10.14687/ihs.v17i2.5980

\subsubsection{Data Collection - Variables and Constructs}

Four sets of dependent variables were operationalized to test the effectiveness of the Gym Orientation Program.

Goodness-of-fit tests supported the premise that the N=128 "Gym Novice" Members in the Panel were representative of the Gym X Member population in terms of Age and Gender.

The independent variable, GOP, participation in the Gym Orientation Program, is categorical, and was coded GOP $=1$, participated in the program, versus GOP $=0$, did not.

The remaining (dependent) variables are listed in their presumed order of causal sequence and include:

(1) Member background characteristics

(2) Initial levels of Goal \& Institutional Commitment

(3) Institutional and Social integration

(4) Secondary levels of Goal \& Institutional Commitment

(5) Intent to Persist

\subsubsection{Construct Reliability and Validity}

Each of the four scales (Institutional Integration, Social Integration, Goal Commitment, Institutional Commitment) loaded uniquely and strongly (factor loadings $>0.6$ ) on 4 distinct factors using Principal Components Factor Analysis with Varimax rotation.

The PCF Varimax converged on four factors accounting for $78 \%$ of the variance in the correlation matrix, supporting the conclusion that the scale factor structure was consistent with both the structure of the source instruments and the conceptual framework. Strong Cronbach alpha scores $(>0.80)$ across all scale items support the internal reliability of the scales.

Table 1 lists the factor loadings and Table 2 displays the Scale Items and associated Cronbach alpha reliability coefficients.

Table 1

Rotated Factor Analysis Components \& Loadings

\begin{tabular}{|c|c|c|c|c|}
\hline \multicolumn{5}{|c|}{ Rotated Component Matrix ${ }^{a}$} \\
\hline & 1 & 2 & 3 & 4 \\
\hline GC1_1 & & 0.774 & & \\
\hline GC1_2 & & 0.863 & & \\
\hline GC1_3 & & 0.835 & & \\
\hline GC2_1 & & 0.753 & & \\
\hline GC2_2 & & 0.691 & & \\
\hline IC1_1 & 0.783 & & & \\
\hline IC1_2 & 0.821 & & & \\
\hline IC1_3 & 0.879 & & & \\
\hline IC2_1 & 0.801 & & & \\
\hline IC2_2 & 0.762 & & & \\
\hline II_1 & & & & 0.866 \\
\hline II_2 & & & & 0.865 \\
\hline II_3 & & & & 0.875 \\
\hline SI_1 & & & 0.884 & \\
\hline SI_2 & & & 0.923 & \\
\hline SI_3 & & & 0.843 & \\
\hline $\begin{array}{l}\text { Extractic } \\
\text { Rotation } \\
\text { a. Rotati }\end{array}$ & $\begin{array}{l}\text { rincipa } \\
\text { trimax v } \\
\text { in } 5 \text { itt }\end{array}$ & $\begin{array}{l}\text { nponen } \\
\text { Kaiser I } \\
\text { ns. }\end{array}$ & $\begin{array}{l}\text { alysis. } \\
\text { nalizatio }\end{array}$ & \\
\hline
\end{tabular}


Koutsoubakis, D. (2020). Testing the effectiveness of a gym orientation program. Journal of Human Sciences, 17(2), $469-484$. doi:10.14687/jhs.v17i2.5980

Table 2

Questionnaire, Scale Items, and Scale Reliability

\section{Entering Member Questionnaire (EMQ)}

\begin{tabular}{|c|c|c|c|c|}
\hline $\begin{array}{l}\text { Scale } \\
\text { Description }\end{array}$ & $\begin{array}{l}\text { Scale } \\
\text { Item }\end{array}$ & Questionnaire Item & Scale Construction & $\begin{array}{c}\text { Cronbach } \\
\text { Alpha }\end{array}$ \\
\hline \multirow{2}{*}{ Background } & Sex & Please state your sex & \multirow{2}{*}{$\mathrm{N} / \mathrm{A}$} & \multirow{2}{*}{$\mathrm{N} / \mathrm{A}$} \\
\hline & Age & Please state your age & & \\
\hline \multirow{3}{*}{$\begin{array}{l}\text { Initial Goal } \\
\text { Commitment }\end{array}$} & GC1_1 & $\begin{array}{l}\text { I am committed to the goal of } \\
\text { improving my fitness }\end{array}$ & \multirow{3}{*}{$\begin{array}{l}\text { Initial_Goal_Commitment } \\
=\left\{G C 1 \_1+G C 1 \_2+G C 1 \_3\right\}\end{array}$} & \multirow{3}{*}{0.843} \\
\hline & GC1_2 & $\begin{array}{l}\text { I am committed to the goal of } \\
\text { improving my body } \\
\text { composition }\end{array}$ & & \\
\hline & GC1_3 & $\begin{array}{l}\text { I am committed to the goal of } \\
\text { looking and feeling better }\end{array}$ & & \\
\hline \multirow{3}{*}{$\begin{array}{l}\text { Initial } \\
\text { Institutional } \\
\text { Commitment }\end{array}$} & IC_1 & $\begin{array}{l}\text { I feel that Gym } \mathrm{X} \text { is the right } \\
\text { gym for me }\end{array}$ & \multirow{3}{*}{$\begin{array}{c}\text { Initial_Inst_Commit }= \\
\left\{I C \_1+I C \_2+I C \_3\right\}\end{array}$} & \multirow{3}{*}{0.857} \\
\hline & IC_2 & $\begin{array}{l}\text { I feel that at Gym X I can stick } \\
\text { to a consistent fitness regime }\end{array}$ & & \\
\hline & IC_3 & $\begin{array}{l}\text { I am confident that I will make } \\
\text { progress at Gym X }\end{array}$ & & \\
\hline
\end{tabular}

\section{Continuing Member Questionnaire (CMQ)}

\begin{tabular}{|c|c|c|c|c|}
\hline $\begin{array}{l}\text { Scale } \\
\text { Description }\end{array}$ & $\begin{array}{l}\text { Scale } \\
\text { Item }\end{array}$ & Questionnaire Item & Scale Construction & $\begin{array}{c}\text { Cronbach } \\
\text { Alpha }\end{array}$ \\
\hline \multirow{2}{*}{$\begin{array}{l}\text { Secondary Goal } \\
\text { Commitment }\end{array}$} & GC2_1 & $\begin{array}{l}\text { Improving my fitness is } \\
\text { important to me }\end{array}$ & \multirow{2}{*}{$\begin{array}{l}\text { Second_Goal_Commit } \\
=\left\{G C 2 \_1+\text { GC2_2 }\right.\end{array}$} & \multirow{2}{*}{0.812} \\
\hline & GC2_2 & $\begin{array}{l}\text { Improving the way I look and } \\
\text { feel is important to me }\end{array}$ & & \\
\hline \multirow{2}{*}{$\begin{array}{l}\text { Secondary } \\
\text { Institutional } \\
\text { Commitment }\end{array}$} & IC2_1 & $\begin{array}{l}\text { Gym X was the right choice for } \\
\text { me }\end{array}$ & \multirow{2}{*}{$\begin{array}{l}\text { Second_Inst_Commit } \\
\quad=\left\{\mathrm{IC} 2 \_1+\mathrm{IC} 2 \_2\right\}\end{array}$} & \multirow[t]{2}{*}{0.870} \\
\hline & IC2_2 & Gym $\mathrm{X}$ is important in my life & & \\
\hline \multirow{3}{*}{$\begin{array}{l}\text { Institutional } \\
\text { Integration }\end{array}$} & II_1 & I feel that I belong at Gym X & \multirow{3}{*}{$\begin{array}{l}\text { Inst_Integrate = } \\
\{\text { II_1+II_2+II_3 }\}\end{array}$} & \multirow{3}{*}{0.905} \\
\hline & II_2 & $\begin{array}{l}\text { At Gym X I have found a } \\
\text { lifestyle }\end{array}$ & & \\
\hline & II_3 & Gym X adds value to my life & & \\
\hline \multirow{3}{*}{$\begin{array}{l}\text { Social } \\
\text { Integration }\end{array}$} & SI_1 & $\begin{array}{l}\text { I have made new friends at } \\
\text { Gym X }\end{array}$ & \multirow{3}{*}{$\begin{array}{c}\text { Social_Integr }=\{\text { SI_1 }+ \\
\text { SI_2 }+ \text { SI_3 }\}\end{array}$} & \multirow{3}{*}{0.912} \\
\hline & SI_2 & Gym X adds to my social life & & \\
\hline & SI_3 & $\begin{array}{l}\text { At Gym X I am surrounded by } \\
\text { like-minded people }\end{array}$ & & \\
\hline Intent to Persist & Persist & $\begin{array}{l}\text { I intend to renew my } \\
\text { Membership when it expires }\end{array}$ & Persist & $\mathbf{N} / \mathbf{A}$ \\
\hline
\end{tabular}




\subsection{Limitations}

The present study adopted a cross-disciplinary approach, looking to the five decades' worth of scholarship and academic research brought to bear within Higher Education, studying Student Attrition. One obvious limitation is that this may not be an appropriate analogy - young people engaged in higher education studies in order to increase both their educational aptitudes and their employment / career prospects are arguably not a close analogue of adults who are free to choose whether, when, where, and how they will exercise.

That said, the analogy does not rest there - rather, the common ground lies in the fact that human beings need to "belong" to the communities in which they participate, or they will simply look to disassociate (drop out). We therefore propose that conceptual models that have been tried and tested extensively in the field of Higher Education Retention research could be usefully adapted / adopted to be used within the domain of the Fitness Industry. We adapt conceptual constructs and framework herein, but much work remains to be done in order to validate these adaptations, including the whole methodological array: theoretical schema, constructs, scales, and instruments. The relationship between the GOP intervention is understood to be mediated though integration and intention to persist - variables that are subject to their own, extensive literature base in Psychology. Given that the study did not use an experimental design, it must be stated that there is an untested likelihood of spuriousness in the results due to the inclusion of these other variables as apparent mediators.

\subsection{Generalizability}

The present study seeks to assess whether a programmatic intervention adapted from a different domain (Higher Education) can be implemented in the context of the Fitness Industry with measurable positive effects. In principle, a successful outcome in the present case suggests the possibility of designing similar intervention programs for broad implementation across commercial fitness organizations. Over and above the practical utility in terms of increasing Member Retention, moreover, is the insight gained by understanding the conceptual processes that lead to the desired outcome; in other words - if the Gym Orientation program can be shown to effectively lead to increased retention, the purpose of the present study is to understand how this happens, via its effect on increasing perceptions of Social and Institutional integration, and its impact on Goal Commitment.

\subsection{Research Ethics}

In the present study, Gym Members were asked whether they would be interested in participating in a free-of-charge Gym Orientation program designed to welcome them to the gym, and to the world of training, fitness, and health. Participation was voluntary, and included positive educational and social experiences.

\subsection{Statistical Analysis \& Data Evaluation}

The first steps in the data analysis focused on establishing the basic data conditions / prerequisites for multivariate analysis of covariance (MANCOVA). SPSS (version 25) was used to run a range of exploratory analyses including visual inspection of descriptive statistics \& plots; tests of normality (Kolgomorov-Smirnoff); Levene's test for equality of variances and the Box test for multivariate equality of covariances; chi-square goodness of fit tests; finally, the KMO measure of sampling adequacy and Bartlett's test of sphericity. Results supported the conclusion that the basic data prerequisites were met, allowing valid use of factor analysis and multivariate analysis of covariance via the General Linear Model.

The next step was to run an exploratory Factor Analysis (Principal Components with Varimax Rotation) in order to examine the instrument factor structure and establish compatibility with the conceptual model. 
In the third step, the SPSS General Linear Model was used to run MANCOVA and a series of univariate (ANOVA \& ANCOVA) analyses in order to investigate the existence of significant differences in perceptions of Institutional \& Social Integration / Goal and Institutional Commitment / Intent to Persist between Gym Members who completed the Gym Orientation Program, versus those who did not.

The variables Initial_Goal_Commitment and Initial_Inst_Commit were used as covariates due to their significant correlations with the set of dependent variables, their weak correlation with the independent variable (GOP), and their location within the conceptual schema.

In the fourth step, the PERSIST variable was cast in the role of a Dependent Variable using Multiple Regression in order to explore its arguable causal dependence on antecedent independent variables in the conceptual schema, \{Secondary Goal Commitment, Secondary Institutional Commitment, Institutional Integration, Social Integration\}.

Finally, recalling the methodological timeline of the present study:

(1) January $2019=$ deployment of the EMQ instrument, N1 $=175$ "Gym Novice" responses

(2) April 2019 - deployment of the CMQ instrument, $\mathrm{N}=128$ follow-up responses

(3) January 2020 - after a 12-month wait, observation of the actual Retention rate (the number of Members who renewed their Membership within 30 days of expiry)

The January 2020 observed level of actual Retention allows us to examine whether participation in the GOP ultimately resulted in significant differential Retention (via simple ChiSquare goodness-of fit test); it also allows examination of the predictive potency of the lineup of variables now cast in the role of predictors of PERSIST (via Multiple Regression) and actual Retention (via non-parametric Chi-Sqaure).

\section{Results}

Examining the potential presence of sex-and-age-based differences first, Chi-Squared goodness-of-fit tests supported the conclusion that Gym Members within the two treatment groups $(\mathbf{G O P}=\mathbf{1}$, participated in the Gym Orientation Program versus $\mathbf{G O P}=\mathbf{0}$, did not) did not differ significantly in terms of sex and/or age group $[\mathrm{p}>0.18]$. This is an important finding, given that Gym Members were not randomly assigned to each treatment level, they voluntarily chose whether to participate in the GOP or not.

Results of running the General Linear Model (GLM) in SPSS produced a significant overall multivariate $[\mathrm{F}(5,120)=2.303, \mathrm{p}>0.000]$. Table 3 displays the Multivariate F-scores for the Covariates.

Table 3

Multivariate Covariate Tests

\begin{tabular}{|c|c|c|c|c|c|c|}
\hline \multicolumn{7}{|c|}{ Multivariate Tests $^{\mathrm{a}}$} \\
\hline Effect & & Value & $\mathrm{F}$ & $\begin{array}{l}\text { Hypothesi } \\
\text { s df }\end{array}$ & $\begin{array}{l}\text { Error } \\
\text { df }\end{array}$ & Sig. \\
\hline \multirow{5}{*}{ Intercept } & Pillai's Trace & 0.448 & $19.443^{\mathrm{b}}$ & 5 & 120 & 0.000 \\
\hline & Wilks' Lambda & 0.552 & $19.443^{b}$ & 5 & 120 & 0.000 \\
\hline & $\begin{array}{l}\text { Hotelling's } \\
\text { Trace }\end{array}$ & 0.81 & $19.443^{\mathrm{b}}$ & 5 & 120 & 0.000 \\
\hline & $\begin{array}{l}\text { Roy's Largest } \\
\text { Root }\end{array}$ & 0.81 & $19.443^{\mathrm{b}}$ & 5 & 120 & 0.000 \\
\hline & Pillai's Trace & 0.663 & $47.242^{\mathrm{b}}$ & 5 & 120 & 0.000 \\
\hline
\end{tabular}


Koutsoubakis, D. (2020). Testing the effectiveness of a gym orientation program. Journal of Human Sciences, 17(2), $469-484$. doi:10.14687/ihs.v17i2.5980

\begin{tabular}{|c|c|c|c|c|c|c|}
\hline \multirow{3}{*}{$\begin{array}{l}\text { Initial_Goal_Commitme } \\
\mathrm{nt}\end{array}$} & Wilks' Lambda & 0.337 & $47.242^{\mathrm{b}}$ & 5 & 120 & 0.000 \\
\hline & $\begin{array}{l}\text { Hotelling's } \\
\text { Trace }\end{array}$ & 1.968 & $47.242^{\mathrm{b}}$ & 5 & 120 & 0.000 \\
\hline & $\begin{array}{l}\text { Roy's Largest } \\
\text { Root }\end{array}$ & 1.968 & $47.242^{\mathrm{b}}$ & 5 & 120 & 0.000 \\
\hline \multirow{4}{*}{ Initial_Inst_Commit } & Pillai's Trace & 0.672 & $49.277^{\mathrm{b}}$ & 5 & 120 & 0.000 \\
\hline & Wilks' Lambda & 0.328 & $49.277^{\mathrm{b}}$ & 5 & 120 & 0.000 \\
\hline & $\begin{array}{l}\text { Hotelling's } \\
\text { Trace }\end{array}$ & 2.053 & $49.277^{\mathrm{b}}$ & 5 & 120 & 0.000 \\
\hline & $\begin{array}{l}\text { Roy's Largest } \\
\text { Root }\end{array}$ & 2.053 & $49.277^{\mathrm{b}}$ & 5 & 120 & 0.000 \\
\hline \multirow{4}{*}{ GOP } & Pillai's Trace & 0.697 & $55.268^{\mathrm{b}}$ & 5 & 120 & 0.000 \\
\hline & Wilks' Lambda & 0.303 & $55.268^{\mathrm{b}}$ & 5 & 120 & 0.000 \\
\hline & $\begin{array}{l}\text { Hotelling's } \\
\text { Trace }\end{array}$ & 2.303 & $55.268^{\mathrm{b}}$ & 5 & 120 & 0.000 \\
\hline & $\begin{array}{l}\text { Roy's Largest } \\
\text { Root }\end{array}$ & 2.303 & $55.268^{\mathrm{b}}$ & 5 & 120 & 0.000 \\
\hline
\end{tabular}

Table 4 displays the MANCOVA results - the overall multivariate effect of the GOP "treatment" level, duly corrected for the joint multivariate effect of the Covariate Variables. Each of the five dependent variables is significantly different $(p>0.000)$ across the two GOP treatment levels.

Table 4

MANCOVA Results

Multivariate Test of Between-Subjects Effects

\begin{tabular}{|llr|r|r|r|r|}
\hline \multirow{2}{*}{ Source } & $\begin{array}{r}\text { Type III } \\
\text { Sum of } \\
\text { Squares }\end{array}$ & df & \multicolumn{1}{c|}{$\begin{array}{c}\text { Mean } \\
\text { Square }\end{array}$} & \multicolumn{1}{c|}{ F } & Sig. \\
\hline \multirow{4}{*}{ GOP } & Second_Goal_Commi & 55.462 & 1 & 55.462 & 94.572 & 0.000 \\
& $\mathrm{t}$ & & & & & \\
& Second_Inst_Commit & 98.962 & 1 & 98.962 & 164.879 & 0.000 \\
& Inst_Integrate & 81.313 & 1 & 81.313 & 20.431 & 0.000 \\
& Social_Integr & 100.111 & 1 & 100.111 & 21.191 & 0.000 \\
\cline { 2 - 7 } & Persist & 12.827 & 1 & 12.827 & 27.673 & 0.000 \\
\hline
\end{tabular}

a. R Squared $=.772($ Adjusted R Squared $=.767)$

Table 5 below displays the results of running univariate ANCOVA analyses for each of the independent variables, GOP as the dependent treatment level. 
Koutsoubakis, D. (2020). Testing the effectiveness of a gym orientation program. Journal of Human Sciences, 17(2), $469-484$. doi:10.14687/ihs.v17i2.5980

Table 5

ANCOVA Results

Dependent Variable: GOP

ANCOVA Tests of Between-Subjects Effects

\begin{tabular}{|c|c|c|c|c|c|c|}
\hline Source & & $\begin{array}{c}\text { Type } \\
\text { III } \\
\text { Sum of } \\
\text { Square } \\
\text { s }\end{array}$ & df & $\begin{array}{l}\text { Mean } \\
\text { Square }\end{array}$ & F & Sig. \\
\hline \multirow{2}{*}{$\begin{array}{l}\text { Second_Goal_Commi } \\
\text { t }\end{array}$} & Hypothesis & 9.818 & 7 & 1.403 & 7.686 & 0.000 \\
\hline & Error & 21.900 & 120 & $.183^{\mathrm{b}}$ & & \\
\hline \multirow{2}{*}{ Second_Inst_Commit } & Hypothesis & 14.196 & 7 & 2.028 & 13.889 & 0.000 \\
\hline & Error & 17.522 & 120 & $.146^{\mathrm{b}}$ & & \\
\hline \multirow[t]{2}{*}{ Inst_Integrate } & Hypothesis & 7.569 & 10 & 0.757 & 3.667 & 0.000 \\
\hline & Error & 24.150 & 117 & $.206^{\mathrm{b}}$ & & \\
\hline \multirow[t]{2}{*}{ Social_Integr } & Hypothesis & 7.507 & 11 & 0.682 & 3.270 & 0.001 \\
\hline & Error & 24.212 & 116 & $.209^{\mathrm{b}}$ & & \\
\hline \multirow[t]{2}{*}{ Persist } & Hypothesis & 6.846 & 3 & 2.282 & 11.377 & 0.000 \\
\hline & Error & 24.872 & 124 & $.201^{\mathrm{b}}$ & & \\
\hline
\end{tabular}

The results are highly statistically significant across all independent variables.

Table 6 makes the same point from a univariate (ANOVA) perspective.

Table 6

Sequential ANOV A Results for Each Variable

\begin{tabular}{|c|c|c|c|c|c|c|}
\hline \multicolumn{7}{|c|}{ ANOVA : GOP } \\
\hline & & $\begin{array}{c}\text { Sum of } \\
\text { Square } \\
\text { s }\end{array}$ & df & $\begin{array}{l}\text { Mean } \\
\text { Square }\end{array}$ & $\mathbf{F}$ & Sig. \\
\hline \multirow{3}{*}{$\begin{array}{l}\text { Second_Goal_Commi } \\
\text { t }\end{array}$} & Between Groups & 93.214 & 1 & 93.214 & 51.903 & 0.000 \\
\hline & Within Groups & 226.286 & 126 & 1.796 & & \\
\hline & Total & 319.500 & 127 & & & \\
\hline \multirow[t]{3}{*}{ Second_Inst_Commit } & Between Groups & 158.579 & 1 & 158.579 & 81.960 & 0.000 \\
\hline & Within Groups & 243.789 & 126 & 1.935 & & \\
\hline & Total & 402.367 & 127 & & & \\
\hline \multirow[t]{3}{*}{ Inst_Integrate } & Between Groups & 123.584 & 1 & 123.584 & 27.100 & 0.000 \\
\hline & Within Groups & 574.596 & 126 & 4.560 & & \\
\hline & Total & 698.180 & 127 & & & \\
\hline \multirow[t]{3}{*}{ Social_Integr } & Between Groups & 141.129 & 1 & 141.129 & 27.406 & 0.000 \\
\hline & Within Groups & 648.839 & 126 & 5.150 & & \\
\hline & Total & 789.969 & 127 & & & \\
\hline \multirow[t]{3}{*}{ Persist } & Between Groups & 20.450 & 1 & 20.450 & 34.463 & 0.000 \\
\hline & Within Groups & 74.768 & 126 & 0.593 & & \\
\hline & Total & 95.219 & 127 & & & \\
\hline
\end{tabular}


Koutsoubakis, D. (2020). Testing the effectiveness of a gym orientation program. Journal of Human Sciences, 17(2), 469-484. doi:10.14687/ihs.v17i2.5980

The conceptual framework underlying the present study makes it interesting to also look at the PERSIST variable as a Dependent Variable with \{Secondary Goal Commitment, Secondary Institutional Commitment, Institutional Integration, Social Integration $\}$ deputed to the role of Independent Variable, via Multiple Regression.

Tables 7, 8, and 9 below display the results of running a Stepwise Linear Multiple Regression on PERSIST versus \{Secondary Goal Commitment, Secondary Institutional Commitment, Institutional Integration, Social Integration\}.

Table 7

Multiple Regression Results (ANOV A Table)

\begin{tabular}{|c|c|c|c|c|c|}
\hline \multicolumn{6}{|c|}{ Multiple Regression ANOVAa } \\
\hline Model & $\begin{array}{l}\text { Sum of } \\
\text { Squares }\end{array}$ & df & $\begin{array}{l}\text { Mean } \\
\text { Square }\end{array}$ & $\mathrm{F}$ & Sig. \\
\hline Regression & 53.133 & 4 & 13.283 & 38.822 & $.000^{\mathrm{b}}$ \\
\hline Residual & 42.085 & 123 & 0.342 & & \\
\hline Total & 95.219 & 127 & & & \\
\hline $\begin{array}{l}\text { a. Dependent Variable: Persist } \\
\text { b. Predictors: (Constant), } \\
\text { Second_Goal_Commit }\end{array}$ & al_Integr, & Inst_In & grate, & ond_Ins & ommit, \\
\hline
\end{tabular}

Table 8

Multiple Regression Results (Coefficients)

\begin{tabular}{|c|c|c|c|c|c|c|}
\hline \multicolumn{7}{|c|}{ Multiple Regression Coefficients ${ }^{a}$} \\
\hline \multirow[b]{2}{*}{ Model } & & \multicolumn{2}{|c|}{$\begin{array}{l}\text { Unstandardized } \\
\text { Coefficients }\end{array}$} & \multirow{2}{*}{$\begin{array}{c}\text { Standardize } \\
\mathrm{d} \\
\text { Coefficients } \\
\text { Beta }\end{array}$} & \multirow[b]{2}{*}{$\mathrm{t}$} & \multirow[b]{2}{*}{ Sig. } \\
\hline & & $\mathrm{B}$ & $\begin{array}{l}\text { Std. } \\
\text { Error }\end{array}$ & & & \\
\hline \multirow[t]{5}{*}{1} & (Constant) & -0.102 & 0.290 & & -0.351 & 0.726 \\
\hline & $\begin{array}{l}\text { Second_Goal_Commi } \\
\mathrm{t}\end{array}$ & 0.101 & 0.042 & 0.185 & 2.391 & 0.018 \\
\hline & Second_Inst_Commit & 0.105 & 0.036 & 0.216 & 2.961 & 0.004 \\
\hline & Inst_Integrate & 0.089 & 0.026 & 0.241 & 3.373 & 0.001 \\
\hline & Social_Integr & 0.119 & 0.025 & 0.342 & 4.792 & 0.000 \\
\hline
\end{tabular}

Table 9

Multiple Regression Model Summary

\begin{tabular}{|c|c|c|c|c|}
\hline \multicolumn{5}{|c|}{ Model Summary } \\
\hline Model & $\mathrm{R}$ & R Square & $\begin{array}{l}\text { Adjusted R } \\
\text { Square }\end{array}$ & $\begin{array}{l}\text { Std. Error } \\
\text { of the } \\
\text { Estimate }\end{array}$ \\
\hline 1 & $.747 a$ & 0.558 & 0.544 & 0.58494 \\
\hline $\begin{array}{l}\text { a. Predictors: (Constant) } \\
\text { Second_Goal_Commit }\end{array}$ & Social_Integr, & Inst_Integrate & Second_- & st_Commit, \\
\hline
\end{tabular}


In summary, we see evidence of strong statistical significance $(p>0.000, R$-square $=0.558)$, supporting the conclusion that the constructs \{Secondary Goal Commitment, Secondary Institutional Commitment, Institutional Integration, Social Integration $\}$ individually and collectively predict reported intent to Persist.

Finally, turning to the ultimate criterion in the context of this study - actual, observed Member Retention in January 2020. The simplest, yet arguably most effective way of looking at this is via a simple Chi-Square test of the cross-tabulation $\{$ GOP $\mathrm{x}$ Retention\}, as below in Table 10.

Table 10

Chi-Square Goodness-of-Fit Test

\begin{tabular}{|c|c|c|c|}
\hline & GOP & GOP & \\
\hline Observed & 0 & 1 & \\
\hline Retention 0 & 32 & 26 & \\
\hline \multirow[t]{3}{*}{ Retention 1} & 26 & 44 & \\
\hline & 58 & 70 & \\
\hline & GOP & GOP & \\
\hline Expected & 0 & 1 & \\
\hline Retention 0 & 29 & 35 & \\
\hline \multirow[t]{2}{*}{ Retention 1} & 29 & 35 & \\
\hline & 58 & 70 & \\
\hline \multirow[t]{2}{*}{ Sig. } & 0.02 & & \\
\hline & GOP & GOP & \\
\hline Observed & 0 & 1 & Total \\
\hline Retention 0 & 32 & 26 & 58 \\
\hline \multirow[t]{3}{*}{ Retention 1} & 26 & 44 & 70 \\
\hline & 58 & 70 & 128 \\
\hline & $45 \%$ & $63 \%$ & $55 \%$ \\
\hline
\end{tabular}

Here we see that, as of January 2020 the actual retention among the $\mathrm{N}=128$ participating Gym X Members:

- Total Retention was $\mathbf{5 5 \%}$

- Among those who participated in the GOP, retention was $\mathbf{6 3 \%}$

- Among those who did not, retention was $45 \%$

- This difference is statistically significant, $\mathrm{p}>0.02$

In other words, members who participated in the GOP had significantly higher retention one year after the completion of the program. 


\section{Discussion}

The statistical analyses discussed above support three broad conclusions:

(1) Collectively and individually, the variables \{Secondary Goal Commitment, Secondary Institutional Commitment, Institutional Integration, Social Integration and Intent to Persist\} were significantly higher for those members who participated in the GOP versus those who did not, even when statistically controlled for background variables (Sex, Age) and initial levels of Goal / Institutional Commitment.

(2) When cast in the role of independent variables, \{Secondary Goal Commitment, Secondary Institutional Commitment, Institutional Integration, Social Integration $\}$ are statistically significant predictors of Intent to Persist.

(3) Finally, there was a statistically significant difference in actual observed member retention 12 months after the GOP intervention between those members who participated in the GOP versus those who did not. Gym X members who participated in the GOP were more likely to renew their memberships on expiry - this is exactly congruent with the hypothesized effect of the GOP, and the outcomes of similar interventions in the domain of Higher Education research (e.g. Koutsoubakis, 1999).

These are encouraging results - the objective of this study was to investigate whether the Gym Orientation Program intervention "worked" in terms of increasing Member Retention. It would appear that the answer is a tentative, yet well-supported "Yes", even though a causal mechanism is not posited.

For insight into likely practical reasons behind the apparent success of the Gym Orientation program a more detailed look at what the GOP actually involved is instructive, Table 11.

Table 11

GOP Contents

\begin{tabular}{|ll|}
\hline \multicolumn{1}{|c|}{ Gym Orientation Program } \\
2 & Total Duration: 4 weeks \\
3 & 2 x per Week Group Gym Workout \\
4 & 2 Diet-Nutrition-Supplementation Seminars \\
5 & Messions of Small-Group Personal Training \\
6 & Membership of WhatsApp Group \\
7 & Access to Trainerize Personal Training App \\
8 & Customized Fitness Program \\
9 & 1 end-of-program BBQ \\
& Open 4-week access to an Instructor \\
10 & "Mentor" \\
\hline
\end{tabular}

As a template intervention, this is arguably a highly intensive program - it is resource intensive and painstaking, aiming to build social relationships and a sense of institutional belonging through carefully focused and activities. The outcome, however - an observed Retention rate of $63 \%$ among the $\mathrm{N}=128 \mathrm{Gym}$ Members who participated in the program - suggests that this was time and effort well spent. 
Koutsoubakis, D. (2020). Testing the effectiveness of a gym orientation program. Journal of Human Sciences, 17(2), $469-484$. doi:10.14687/ihs.v17i2.5980

\section{Conclusion}

The author is not aware of any prior efforts to apply learnings from the field of Higher Education Research to the domain of the Fitness Industry in the context of investigating Attrition / Retention.

Just like scholars in Higher Education have looked for inspiration far afield to research in Sociology \& Psychology in order to adapt and adopt useful theoretical frameworks and methodological approaches, we propose herein that the same approach can effectively and usefully be brought to bear in Fitness Industry research.

\subsection{Usability of Study Results}

The present study produced encouraging results that require replication and validation in order to demonstrate broader usability in the industry. The data support the conclusion that a Gym Orientation Program designed to increase Member Retention did just that, by leading to increased perceptions of Social and Institutional Integration, increased levels of Goal and Institutional Commitment. Scholars and fitness operation managers alike may use both the Gym Orientation program used herein and the questionnaire instruments developed in order to deploy similar interventions and measure the outcomes.

\section{References}

Astin, A. W. (1984). "Student involvement: A developmental theory for higher education". Journal of College Student Personnel Vol. 40, pp. 518-529.

Astin, A. W. (1993). Assessment for excellence: The philosophy and practice of assessment and evaluation in higher education. Oryx Press.

Bean, J. P. (1980). "Dropouts and turnover: The synthesis and test of a causal model of student attrition". Research in Higher Education, Vol.12, pp.155-187.

Bean, J. P. (1983). "The application of a model of turnover in work organizations to the student attrition process". Review of Higher Education, Vol. 12 No.6, pp. 129-148.

Gonçalves, C., \& Diniz, A. (2015). "Analysis of member retention in fitness through satisfaction, attributes perception, expectations and well-being". Portuguese Journal of Marketing / Revista Portuguesa de Marketing, Vol. 34, pp. 65-76.

Kirby, M.B. (2015). Toward a New Predictive Model of Student Retention in Higher Education: An Application of Classical Sociological Theory. Journal of College Student Retention: Research, Theory \& Practice, Vol. 17 No. 2, pp. 138-161

Koutsoubakis, D. (1999). "A test of effectiveness of a one-term freshman orientation program at the foreign campus of an accredited private American university". Journal of The First-Year Experience, Vol.11 No.2, pp. 33-58.

Lynch, D. (2003). "Maximizing revenue opportunities". ACAM's Health \& Fitness Journal, Vol. 7 No.3, pp.22-23.

Macintosh, E., \& Doherty, A. (2007). "Reframing the service environment in the fitness industry". Managing Leisure, Vol.12 No.4, pp. 273-289.

Mavropoulou, M., Kouthouris, C., \& Alexandris, K. (2013). "Investigating customer's motives, service quality, commitment and intentions for future participation in private gym centers". Hellenic Journal of Sport \& Recreation Management, Vol.10 No.1, pp. 44-57.

Milem, J. F., \& Berger, J. B. (1997). “A modified model of college student persistence: Exploring the relationship between Astin's theory of involvement and Tinto's theory of student departure". Journal of College Student Development, Vol. 38 No.4, pp. 387-400.

Pascarella, E. T. (1980). "Student-faculty informal contact and college outcomes". Review of Educational Research, Vol. 50, pp. 545-595. 
Koutsoubakis, D. (2020). Testing the effectiveness of a gym orientation program. Journal of Human Sciences, 17(2), 469-484. doi: $10.14687 /$ ihs.v17i2.5980

Pascarella, E. T., \& Terenzini, P. T. (1980). "Predicting freshman persistence and voluntary dropout decisions from a theoretical model". Journal of Higher Education, Vol. 5 No. 1, pp. 60-75.

Strumpf, G., \& Hunt, P. (1993). "The effects of an orientation course on the retention and academic standing of entering freshmen, controlling for the volunteer effect". Journal of The Freshman Year Experience, Vol. 5 No.1, pp. 7-14.

Tinto, V. (1975). "Dropout from higher education: A theoretical synthesis of recent research". Review of Educational Research, Vol. 45 No.1, pp. 89-125.

Williams, R., Smiley, E., Davis, R., Lamb, T. (2018). "The Predictability of Cognitive and Noncognitive Factors on the Retention Rate among Freshmen College Students". The Journal of Negro Education Vol. 87 No. 3, pp. 326-337

Yucel-Aybat, O., Gibney, R., Masters, M.F., Amlie, T.T. (2018). “A Social Exchange Perspective on Student Retention and University Support Intentions", Philanthropy \& Education Vol. 1, No. 2, pp. 1-27 